\title{
Research on Training Base's Expansion of Scientific Popularization Function in Higher Vocational Colleges
}

\author{
Zhixin Feng, Shang Wang*, Xuelei Wang \\ School of Automotive Engineering, Beijing Polytechnic, Beijing 100173, China \\ *Corresponding author: Shang Wang, wangshang@bpi.edu.cn
}

\begin{abstract}
Based on the needs of regional industrial development and technical personnel training, the training base for technical skill as the core function has effectively enhanced the development of vocational education. However, at present, the training base in vocational colleges is mainly applied for students' teaching, and the overall utilization rate is low. It is of great importance in the rational application of software and hardware resources onto the training base to widely carry out popular science activities. The importance of training base construction and scientific popularization is expounded. On this basis, the research team took the S\&T racing training base as a case to study its expandable scientific popularization function. The practice results show that using the resources of the training base to carry out scientific popularization activities can greatly improve teenagers' interest in automobile technology. More training bases in vocational colleges should expand the function of scientific popularization.
\end{abstract}

Keywords: Scientific popularization; Training base; Vocational colleges; Vocational education; Teenagers

Publication date: December 2021; Online publication: December 23, 2021

\section{Introduction}

At present, China's economy is in a critical period of transformation and development, which requires a large number of technical and skilled talents. Under such circumstances, vocational education should accelerate reform and development, actively serve major national development strategies, further meet market demand, optimize and adjust professional structure, train technical and skilled talents on a larger scale, build a high-quality vocational education system to adapt to the new development pattern, and effectively support the high-quality development of China's economy ${ }^{[1-4]}$. The construction of the training base has effectively cultivated skilled talents with strong practical capability and greatly promoted the development of vocational education. There is no doubt that a large number of training bases have effectively promoted school and cooperation, enriched teaching methods and improved the quality of talent training. However, some problems also arise in the operation of the training bases. One of the common obvious problems is the high vacancy rate, which is an indication of invisible waste of resources ${ }^{[5-6]}$. In addition to the education of students, social service is also an important responsibility of vocational colleges. How to tap the potential value of the training base and improve its social service ability is a very important and therefore, a valuable research project.

Scientific quality is an important part of national quality. Scientific popularization is a good way to strengthen the country and enlightens the wisdom of the people. Scientific ability is even closely related to the prosperity of the country. As a driving force of the national future development, teenagers' scientific quality determines the persistence and future development direction of national strength ${ }^{[7-8]}$. Science 
popularization education not only urges young people to learn and acquire scientific and technological knowledge and master scientific and technological methods, but also helps them form a scientific spirit and establishes a world outlook in sciences. Scientific popularized education can also help teenagers establish correct outlook on life and values, and lay the ideological foundation of scientific rationality, pragmatism and truth-seeking attribute.

With the rapid development of vocational education in China, vocational colleges are playing a more and more important role in serving social and economic development, and their social service capability is becoming stronger. However, at present, the social service in vocational colleges is mainly connected to the production line of industrial enterprises, and its service objectives are mainly professional and technical personnel.

Science popularization should also be one of the important contents of social service in vocational colleges. Nevertheless, the experience in vocational colleges is still insufficient in scientific popularization education open to the public, especially the youth scientific popularization education. The smooth development of science popularization is inseparable from professional hardware facilities, and the training base of vocational colleges has such resources. When the training base is vacant, various scientific popularization activities for teenagers can be organized, which not only popularizes scientific and technological knowledge, but also improves the utilization rate of the base and introduces some operating funds for the base.

In order to fully tap the potential of the training base and explore its scientific popularization function, the research took the automobile manufacturing as an example.

\section{Preparation of scientific popularization work}

Beijing Polytechnic organized a scientific popularization activity with China International Publishing Group (CIPG). The research team took advantage of this opportunity to explore the scientific popularization function of the training base for racing cars.

\subsection{Object}

The website of CIPG (China.com.cn) organized a delegation of 21 "little journalists" to visit Beijing Polytechnic. These little journalists are all elementary school students. Given the pupils' weak cognitive abilities, the team was well prepared.

\subsection{Preparatory process}

The research team made meticulous preparations for this scientific popularization activity. The general logical diagram of scientific popularization work is shown in Figure 1.

(1) The research team carefully analyzed the characteristics of elementary school students. There are two situations that need to be paid attention to. The first one is that children should be interested in science popularization, otherwise it will be difficult to carry out science popularization. Secondly, students' learning and understanding ability should be taken into account, and very complex knowledge should not be considered.

(2) After discussion, the research team decided to use the racing training base for scientific popularization work. The main consideration is the children's interests.

(3) The content of this scientific popularization activity is mainly about the design and manufacturing technology of racing cars. On the one hand, teachers should explain the design and manufacturing process of the racing car. On the other hand, the research team should pay attention to cultivating students' spirit of exploration and patriotism. 
(4) The test drive experience is essential. Students' safety should be fully considered during the test drive, and the research team manually set the maximum speed of the test car.

(5) Interviews with these students are also important because they are "little journalists". The research team hopes to consolidate the results of science popularization through interviews and cultivate the children's character of being earnest and hardworking.

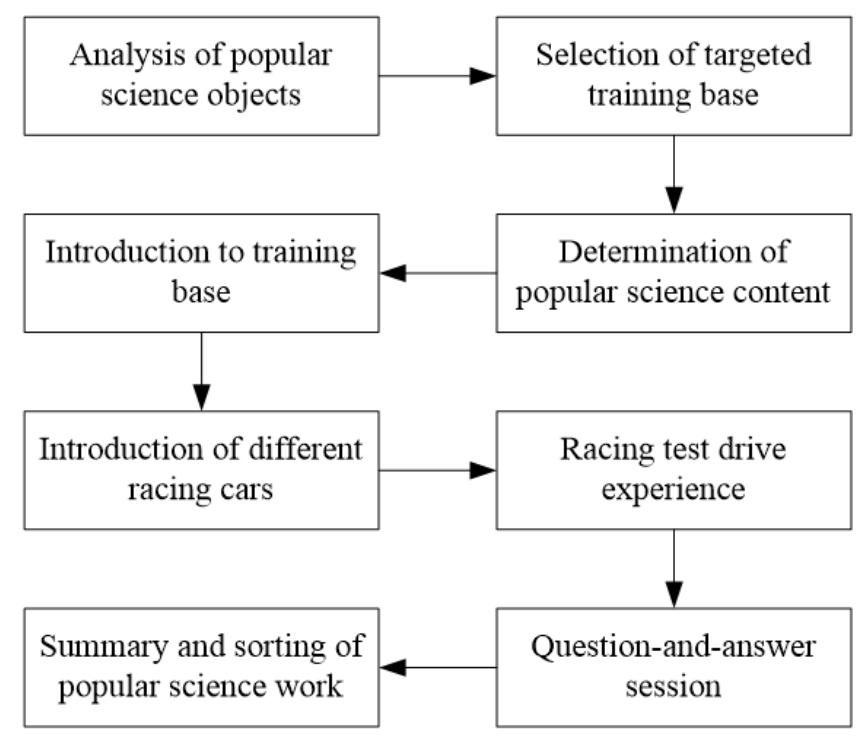

Figure 1. Logical diagram of scientific popularization work

\section{Practice}

On June 19, 2021, Beijing Polytechnic warmly welcomed 21 "little journalists" of China Internet Information Center. The little journalists, aged 9 to 12, were from an elementary school in Beijing. The theme of the scientific popularization activity was racing car. The little journalists visited and learned the racing knowledge and also experienced the test drive of the racing car. This scientific popularization activity not only trained the interview skills of these journalists, but also enriched their understanding of racing culture and cutting-edge knowledge.

\subsection{Scientific popularization teaching and test drive}

Five teachers and eight racing team members (students) formed a scientific popularization team. The following contents were mainly introduced to the little journalists:

(1) Combined with the specific racing car, the scientific popularization team explained the main components of the racing car to the students, including gasoline engine, continuously variable transmission (CVT), reducer, rear drive, four-wheel-drive, steering rod, wheel motor, pedal, air inlet, cylinder, differential and so on.

(2) The scientific popularization team explained the process of making a racing car to the students. Car production is a very complex engineering process. First of all, the designer needs to use professional software for 3D modeling, and design the size of each component, as shown in Figure 2(a) and Figure 2(b). The second step is to make various parts and polish them repeatedly. The third step is welding to put all the parts together in order. Some parts cannot be welded and can only be joined with screws or rivets. In step four, the car will undergo dozens of tests and adjustments. 
(3) In order to learn more about scientific popularization racing, the scientific popularization team assembled a semi-finished car with the little journalists, as shown in Figure 2(c) and Figure 2(d). The children are particularly active: some help find wrenches, and some help the teacher move the car.

(4) The best feature of a racing car is its speed. To go fast, the car has to be light. As a result, many parts are made of carbon fiber. Carbon fiber is only $25 \%$ the mass of steel for the same volume, but it is 10 times harder.

(5) The children were also asked some questions about racing knowledge. Is it better to have bigger battery for an electric racing car ? The answer is "no." On one hand, it has more power and large battery volume, which makes the car run farther. On the other hand, the large size of the battery will also make the car too heavy and cause the car to run too slowly. The students not only learned about racing, but also learned to look at problems comprehensively.

(6) The most unforgettable thing for the children was the test drive, as shown in Figure 2(e) and Figure 2(f).

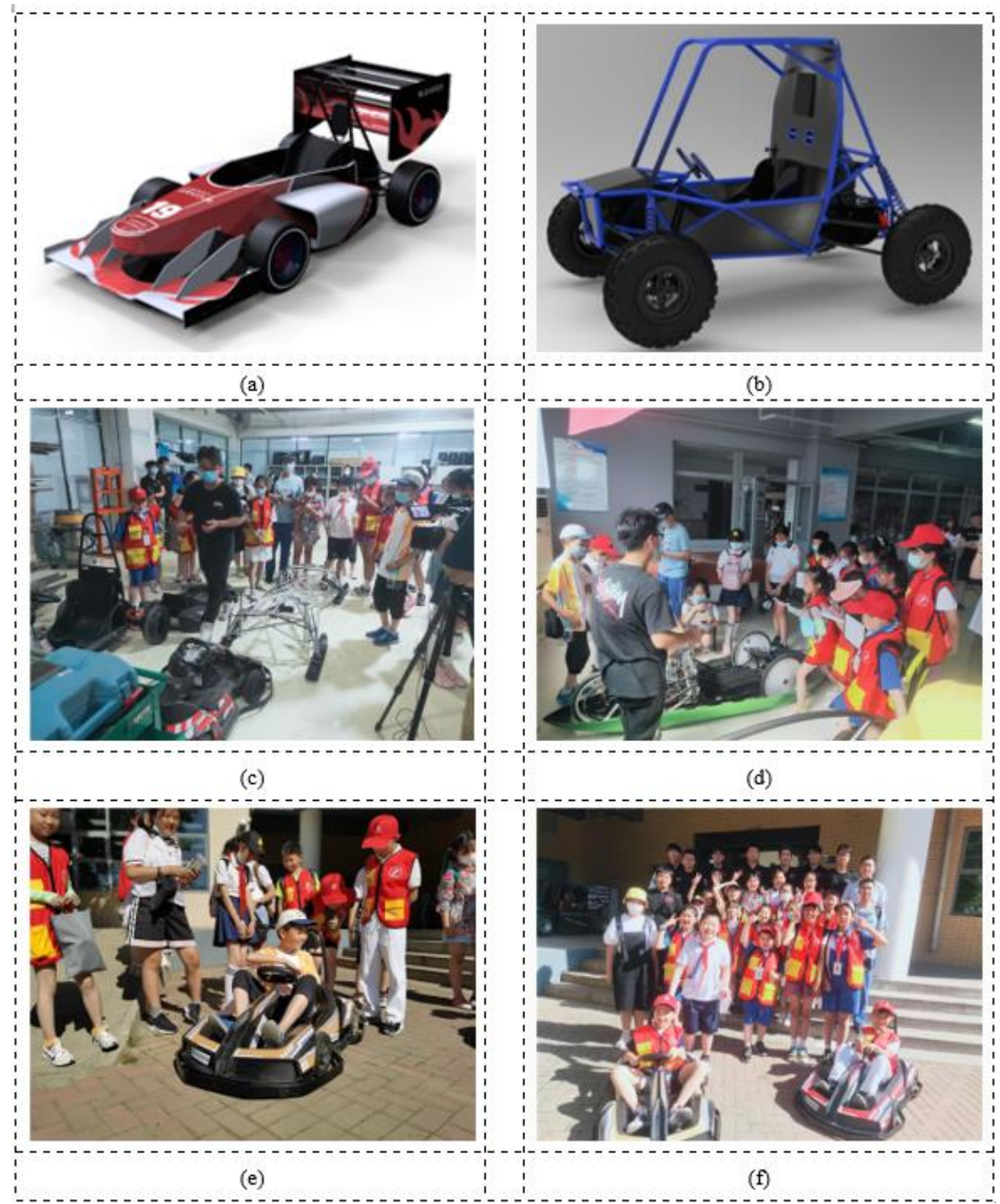

Figure 2. Little journalists learned knowledge and drove cars in the training base 


\subsection{Interview exercises the questioning ability of little journalists}

The research team organized a question-and-answer session in order to better popularize knowledge of racing. The young reporters eagerly asked the racers and teachers some questions.

The first little journalist asked: how does the S\&T fleet usually train? Will it feel difficult? Mo Chen, a racing driver of Beijing Polytechnic, replied that there is no special way in routine training, but to practice hard. He usually wears racing clothes and helmets, drive the car, train around the track all the time, and never stop regardless the weather. Although sometimes he feels difficult, but the goal is firm, which is a powerful motivator to support himself to go on.

The second little reporter asked: what difficulties will be encountered on weekdays, which ones are impressive, and how to overcome them? Han Meng, a teacher of Beijing Polytechnic, replied that the most difficult time for racing related work is the stage of assembling the racing car after the design is completed, because various unexpected problems will be encountered during such period. For example, if processing difference of processed parts does not meet design requirements, it will need secondary processing, and the previous efforts may be wasted. No matter how hard it is, as a team, the fleet must confront it. Each student of the fleet has a clear division of labor. They work together to overcome difficulties, find solutions to problems, design, assemble and adjust the car. The staff often works late trying to adjust and make the car better.

The third little reporter asked: what supports the leader to lead the staff until now? Siqi Liu, the team leader of Beijing Polytechnic, replied that everyone in the team has the same dream and same hobby, so they can unite to form this team. Everyone is striving for a common dream.

The fourth little reporter asked: does training affect learning? How long do they train and rest every day? Mo Chen said that training will not occupy learning time. When anyone cannot go to professional venues for training, he will stay in school to exercise, because physical fitness is too important for a racing driver. The intensity of formal training is very high. Sometimes it takes a day to practice in a racing car.

Through the interview, the children had a deeper understanding of the structure and manufacture of the racing car. To win the championship in the competition, the hard work of the players is indispensable.

\section{Retrospect and prospect}

With the strong support of the state, the training base of vocational colleges has developed rapidly and effectively promoted the education and teaching reform. While making achievements, some existing problems should also be paid attention to. A common problem is that the vacancy rate of the training base is too high, which is also a waste of resources. There is no doubt that the maintenance of the training base is very costly as the funds were invested in hardware facilities in the early stage and spent on the site, supporting facilities, manpower and other operations. If the fixed asset investment of a training base is 30 million yuan (depreciation for 15 years), the annual total operation investment (financial/human resources) is 500,000 yuan. If the training base has only 50 days of teaching tasks, it is equivalent to an investment of 50,000 yuan per day. However, if it can meet other nonteaching tasks for 100 days, such as undertaking social training for 50 days and science popularization for 50 days, the operation investment of the base will be about one-third of the original. Obviously, it is very meaningful to reasonably use the practical training base of vocational colleges to carry out popular science activities.

The scientific and technological innovation and scientific popularization are two ways of realizing innovation and development, and scientific popularization should be placed in the same important position as scientific and technological innovation.

\section{Conclusion}

The main work and conclusions of this paper are as follows: 
(1) We expounded the importance of the construction of practical training base and its promoting effect on vocational education. The significance of science popularization education is analyzed.

(2) The science popularization education was carried out by using the training base of racing cars. On the one hand, the science popularization education expanded the children's knowledge. On the other hand, it improves children's interest in learning and their love of automobile knowledge.

\section{Acknowledgments}

The research team thanked the Project of Beijing Office for Education Sciences Planning.

\section{Funding}

The research work in this paper was supported by the following two funds: "A case study on the construction of pilot test base of technical skill innovation service platform in higher vocational colleges" (Project number: CGDB21208) and "Research on the key elements of the construction of vocational education and training system in higher vocational colleges" (Project number: CCDB2020135).

\section{Disclosure statement}

The authors declare that there is no conflict of interest.

\section{Author contributions}

X.W. sorted out the manuscripts and modified the format. S.W. contributed significantly to manuscript preparation. Z.F. helped perform the analysis with constructive discussions.

\section{References}

[1] Jiang D, 2011, Reform and Development of Vocational Education in China: Experiences and Rules. Vocational and Technical Education, 32(19): 5-10. https://doi.org/10.3969/j.issn.10083219.2011.19.002

[2] Shi W, 2013, Issues and Problems in the Current Development of Vocational Education in China. Chinese Education \& Society, 46(4): 12-21. https://doi.org/10.2753/CED1061-1932460401

[3] Manfred W, 2010, Vocational Education and Training and Human Capital Development: Current Practice and Future Options. European Journal of Education, 45(2): 181-198. https://doi.org/10.1111/j.1465-3435.2010.01424.x

[4] Moodie G, 2020, Skills for Human Development: Transforming Vocational Education and Training. Journal of Vocational Education \& Training, 72(3): 461-464. https://doi.org/10.1080/13636820.2019.1627065

[5] He R, Long Z, Yu Z, 2019, Discussion on the Importance of University-Enterprise Joint Training Base for Personnel Training in Higher Vocational Colleges. Journal of Green Science and Technology, 8(11): 304-305. https://doi.org/10.3969/j.issn.1674-9944.2019.11.131

[6] Wu X, 2009, Building Numerical Control Training Base with High Standard and Improving the Running Level of Numerical Control Specialty - Some Thoughts on Building Provincial High-Level Professional Training Base. East China Normal University. https://doi.org/10.7666/d.y1608112 
[7] Si N, 2011, Study on Countermeasures of Popular Science Work in China in the New Period. Zhengzhou University. http://doi.org/10.7666/d.y1930141

[8] Li J, 2019, Thinking About the Integration Development of Science and Technology Innovation and Science Popularization. Anhui Science and Technology, 8(7): 5-7. http://doi.org/10.3969/j.issn.10077855.2019.07.002 